\title{
An International Comparison of Cases of Forest Product Development: Overview, Description and Data Requirements
}

\author{
Brian Belcher and Manuel Ruiz-Pérez
}

\begin{abstract}
SUMMARY
With increased attention to and investment in forest products (especially "NTFP"), there is a real need for more systematic understanding of the true role and potential of forest products to achieve development and conservation objectives. Information is required to improve the effectiveness of investment and policy interventions. There is a rich base of information from many case studies and development projects that have been done on various aspects of forest product development. But, this information has been assembled in an ad-hoc fashion, using a range of methods, at different scales, and focusing on different elements of the forest product production, processing and marketing systems. Work is needed to document and compare cases using consistent terms and definitions for an appropriate range of variables. This paper describes a method to do this. It involves collating information from many cases that have already been studied. Cases will be documented and described using a standardized set of descriptors, and this data matrix will be used as the basis for the comparative analysis. Exploratory data analysis will be used to outline patterns, gradients of variability, clusters of cases and key variables associated with them. The goal is to create typologies of cases, identify conditions associated with particular kinds of development and conservation outcomes, and identify and test hypotheses about forest product development. The ultimate goal is to provide guidance for action-oriented interventions based on forest products; that is, to identify conditions and "types' of cases that are amenable to development interventions, as well as to flag "types" of cases that may not be good investments. This paper provides guidelines for research collaborators. It describes the categories of information (geographic setting; biological and physical characteristics of the product; characteristics of the raw material production system; socio-economic characteristics of raw material production system; institutional characteristics of raw material production system; characteristics of the processing industry; characteristics of the market and marketing system; outside Interventions, and; outcomes of forest product commercialization) and provides definitions and rationales for the various descriptors used.
\end{abstract}

CENTER FOR INTERNATIONAL FORESTRY RESEARCH

Office address: Jalan CIFOR, Situ Gede, Sindangbarang, Bogor 16680, Indonesia

Mailing address: P.O. Box 6596 JKPWB, Jakarta 10065, Indonesia

Tel.: +62 (251) 622622; Fax: +62 (251) 622100

E-mail: cifor@cgiar.org

Web site: http://www.cifor.cgiar.org 


\section{TABLE OF CONTENTS}

$\begin{array}{ll}\text { SUMMARY } & 1\end{array}$

$\begin{array}{ll}\text { INTRODUCTION } & 3\end{array}$

$\begin{array}{ll}\text { BACKGROUND AND RATIONALE } & 3\end{array}$

$\begin{array}{ll}\text { CRITERIA FOR CASE SELECTION } & 4\end{array}$

$\begin{array}{ll}\text { THE UNIT OF ANALYSIS } & 5\end{array}$

$\begin{array}{ll}\text { DESCRIBING THE SYSTEM - CATEGORIES OF DATA } & 7\end{array}$

$\begin{array}{lr}\text { GEOGRAPHIC SETTING } & 8\end{array}$

$\begin{array}{ll}\text { CHARACTERISTICS OF THE PRODUCT } & 8\end{array}$

$\begin{array}{lr}\text { CHARACTERISTICS OF THE PRODUCTION SYSTEM } & 9\end{array}$

$\begin{array}{lr}\text { ECOLOGICAL IMPLICATIONS OF PRODUCTION } & 10\end{array}$

SOCIO-ECONOMIC CHARACTERISTICS OF THE RAW MATERIAL

PRODUCTION AREA 10

INSTITUTIONAL CHARACTERISTICS OF RAW MATERIAL PRODUCTION 11

$\begin{array}{ll}\text { POLICIES AFFECTING RAW MATERIAL PRODUCTION } & 11\end{array}$

$\begin{array}{lr}\text { CHARACTERISTICS OF THE PROCESSING INDUSTRY } & 12\end{array}$

$\begin{array}{lr}\text { CHARACTERISTICS OF TRADE AND MARKETING } & 13\end{array}$

$\begin{array}{lr}\text { OUTSIDE INTERVENTIONS } & 13\end{array}$

$\begin{array}{lr}\text { DEVELOPMENT AND CONSERVATION OUTCOMES } & 13\end{array}$

$\begin{array}{lr}\text { ACKNOWLEDGEMENTS } & 14\end{array}$

$\begin{array}{lr}\text { REFERENCES } & 15\end{array}$

$\begin{array}{lr}\text { ANNEX I. DESCRIPTORS } & 17\end{array}$

$\begin{array}{ll}\text { ANNEX II. EXAMPLE OF DATA RECORDING SPREADSHEET } & 25\end{array}$ 


\title{
An International Comparison of Cases of Forest Product Development: Overview, Description and Data Requirements
}

\author{
Brian Belcher ${ }^{*}$ and Manuel Ruiz-Pérez ${ }^{\star *}$
}

\section{INTRODUCTION}

Increased recognition of the many values of forests has led to new interest and effort to develop forest products as a means to achieve both development and conservation objectives. Governments, NGOs, community groups, and development agencies are actively seeking ways - through policy, investment, green marketing, and other interventions - to "develop" forest products. A new literature has emerged over the past fifteen to twenty years and significant investments have been made in numerous projects (see reviews such as Neumann and Hirsch 2000; Townson 1994; Ruiz-Pérez and Arnold 1996). Much of this investment is based on the premise that improving prices for producers, adding value locally through increasing post-harvest processing and improving local organizations, can lead to longterm economic and political gains for these groups. Some also argue that these kinds of interventions can lead to forest conservation. And yet, understanding of the true role and potential of forest product development to contribute to human development or conservation, based as it is on untested theory and scattered and inconsistent case-based research, remains limited.

This project is working to improve this understanding through a comparative analysis of a wide range of cases of forest product development. We aim to collate information from many cases that have already been studied, to document and describe the cases using a standardized set of descriptors and to conduct a series of exploratory analyses. The goal is to:

- create typologies of cases

- identify conditions associated with particular kinds of development and conservation outcomes, and

- develop and test hypotheses about forest product development.
The purpose is to provide guidance for actionoriented interventions based on forest products; that is, to identify conditions and 'types' of cases that are amenable to development interventions, as well as to flag "types" of cases that may not be good investments.

This paper provides guidelines for collaborators in this research. It briefly presents the background and rationale for the study, describes the approach that will be followed and sets out specifications for data collection for individual cases.

\section{BACKGROUND AND RATIONALE}

There is a rich body of information on many aspects of commercial forest product development. This information includes numerous case-based studies of different elements of forest product systems (mainly in the area of "non-timber forest products", or NTFP) and results from development projects that have invested in forest product development. Many interventions have been tried at the project level, including various combinations of technical, institutional and financial support for forest product production, processing and marketing, with mixed success (see or example various reports from the Biodiversity Conservation Network). As well, larger, cross-cutting interventions have been attempted, including green markets, "fair trade" initiatives and efforts to promote NTFP certification (Shanley et al. forthcoming).

However, it is difficult to build a theoretical framework from this basis. The information has been gathered using a range of methods, at

\footnotetext{
"Center for International Forestry Research.

*Center for International Forestry Research and Universidad Autónoma de Madrid.
} 
different scales and focusing on different elements of the forest product production, processing and marketing systems. Work is needed to document and compare cases using consistent terms and definitions for an appropriate range of variables.

This research will synthesize lessons from 50-60 cases (15-20 each in Latin America, Africa and Asia) that have already been researched and analyzed, applying a uniform comparative analytical approach. A range of descriptors (variables) has been identified based on a review of the literature and the authors' experience. These variables have been recognized in the literature as being important in some aspect of forest product development. They are not treated here as normative variables - there is no presupposition that it is "better" or "worse" to have or not to have certain characteristics. The objective is to find out which characteristics tend to be associated with which other characteristics, and so create a typology of cases. We also want to discover which sets of characteristics, or "types" of cases, tend to be associated with what kinds of human development and conservation outcomes. We are hopeful that this information will be a valuable addition to the management and policy debate.

The comparative methodology is based on that developed by Ruiz-Pérez and Byron (1999). It uses exploratory statistical techniques to find patterns, develop typologies, identify key context variables and analyze their relationship with observed development outcomes. The approach involves describing the selected cases according to a standard set of descriptors (variables discussed below) to develop a case-study matrix. We will then use exploratory data analysis to outline patterns, gradients of variability, clusters of cases and key variables associated with them. We want to develop a useful typology of cases, identify key variables (those with maximum explanatory power) and investigate relationships between particular classes of forest products production-to-consumption systems and their development and conservation outcomes.

In addition to the statistical analysis, the relatively large database of cases, characterized using a standard format, will offer a unique opportunity for qualitative analyses. We intend to publish summaries of the case descriptions in three volumes (by region) for ease of use by other researchers.
In order to capture all of the relevant variability, the analysis will be based on a production-toconsumption systems (PCS) approach. That is, the case descriptions and the comparative analysis will consider the whole system, from production of raw material through to final market, including social, economic, technological and ecological aspects of the production systems, of the products and of the market (Belcher 1997, 1998).

The following categories of information will be addressed:

- Geographic setting

- Biological and physical characteristics of the product

- Characteristics of the raw material production system

- Ecological implications of production

- Socio-economic characteristics of the raw material production system

- Institutional characteristics of raw material producers

- Policies affecting raw material production

- Characteristics of the processing industry

- Characteristics of the trade and marketing system

- Outside Interventions

- Outcomes of Forest Product Commercialization

More detail is provided below.

\section{CRITERIA FOR CASE SELECTION}

The purpose of this study is to compare cases of commercial forest product development. The importance of forest products in subsistence systems is by now well recognized. Efforts are needed to protect those benefits where their loss would lead to hardship for users. However, the reasons that many of these products are important, such as low-cost access, availability during times of shortage and a lack of suitable alternatives, does not necessarily make them suitable for commercial development. Indeed many subsistence products are inferior goods ${ }^{1}$ that will be displaced if and when the people who are using them have physical or economic

\footnotetext{
${ }^{1}$ In economic terms, an "inferior good" is one for which demand decreases as incomes rise and people are able to purchase better or more desirable alternatives.
} 
access to alternatives. Such products are important in the subsistence context, but they are unsuitable as targets for investment.

We are interested to understand the context, the conditions and the outcomes of commercial development of forest products. We need to focus our analysis on products that have true commercial potential. Therefore, the first criterion for inclusion in the comparative analysis is that the forest product has significant demonstrated commercial/trade value; that is, the product is traded in the cash economy. The same product may also have subsistence uses.

One of the premises of this study is that there is a broad base of information available on different forest product systems, but that the information is not suitably comparable. To optimize the use of available information and to minimize the costs of data collection, we want to encourage a consistent approach to documenting available information. We expect that it will be necessary in some cases to do further data collection to supplement the available data, but hope that we can find a sufficient number of cases with a large proportion of the required data already available, even if it needs to be reformatted. The second criterion for case selection then is that the production, processing and marketing system has been researched and documented with data available on approximately $70 \%$ of the variables.

The statistical analysis will help to identify patterns and trends, but it is just a tool for the overall analysis. Moreover, it is simply impossible to include all variables in the data set. The analysis will require the expert judgement of researchers/analysts who have detailed personal knowledge of the case. The third criterion for case selection then is that there is an individual or team of experts willing to collect additional data to complete the case documentation and to participate in the comparative analysis.

Finally, an effort will be made to include a broad range of cases, representing, for example, divergent geographic and climatic conditions, management systems, market size and kind (local, regional, international) and development histories (i.e., "spontaneous" commercial development versus cases that have received external interventions/support for commercialization). Therefore, the fourth selection criterion will be to include adequate representation of a range of cases.

\section{THE UNIT OF ANALYSIS}

The first and most important step in the process is the definition of the case. One of the premises of this work is that we will be comparing cases that have already been studied and are reasonably well understood. The case corresponds to the study area, or a larger associated area to which available information and analysis can reasonably be extrapolated and the downstream and upstream market linkages.

The case includes all of the following components:

The raw material production area - the forest and/or forest-farm area that has been studied and about which there is reliable socio-economic and ecological information. It might be a major production area of the product, though production of this forest product might not be the dominant economic activity in the area. The concept is analogous to the concept of a "catchment area" in hydrology - the area of land where the forest product is produced. It is sufficient that forest product production and marketing is a significant economic activity for a sub-set of the people living and working in the area. The physical size of the area should be within the range of 10,000 ha to 100,000 ha. It may be one contiguous area or several smaller "centres" of forest product production. The actual case definition may be somewhat arbitrary - it is to be determined by the researcher responsible for the case description. Once the definition has been made, however, it is critical to be consistent in applying it when quantifying all variables. It is important to note that the geographical circumscription applies only to the raw material production area - the overall case also includes trade, processing and marketing that may, and in most cases probably does, take place outside of the raw material production area. Also, there may be other areas in the country or the region where the forest product is grown that are not included as part of the case. 
Three examples of raw material production areas are shown in figures $1-3$. Figure 1 represents a classic example in which people live in small villages within the forest. They engage in agriculture in small clearings in the forest and also harvest forest products from the surrounding forest. The raw material production area is defined to include the forest area. agricultural area associated with those villages. Villages that fall within this area, even if they are not involved in the PCS, should be included.

Figure 3 represents a situation where the raw material collectors live further from the forest and near a large urban centre. The raw material production area is defined to

Fig. 1. Example of a Raw Material Production Area
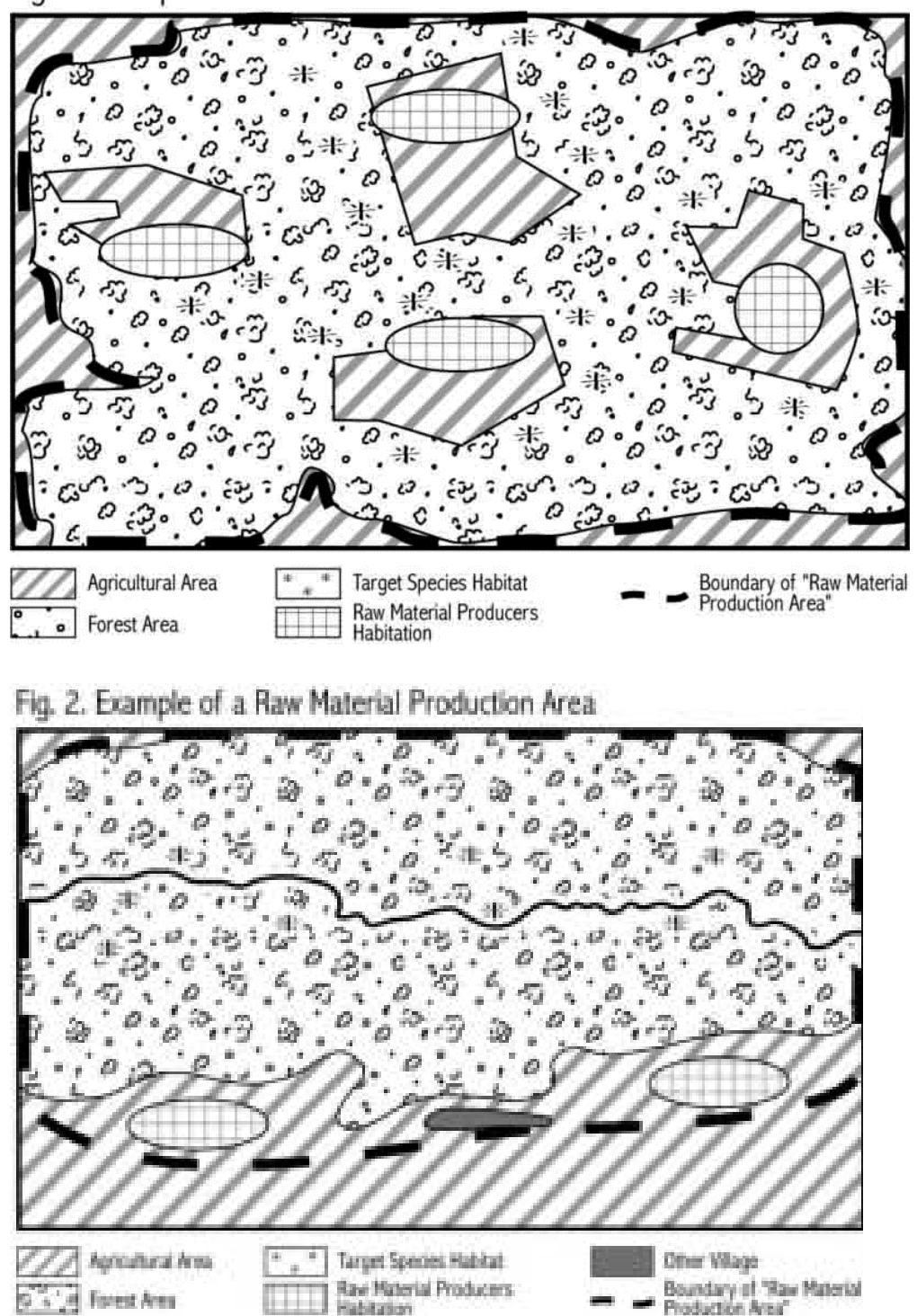

In the second example (figure 2) the raw material collectors live in villages outside the forest, but travel into the nearby forest to collect forest products. The raw material production area is defined to include the forest area as well as the village area and the include the producers villages but to exclude the urban area. An infinite number of other situations exist - individual researchers will be best placed to determine an appropriate definition, based on the principles above. 
Fig. 3. Example of a Raw Material Production Area

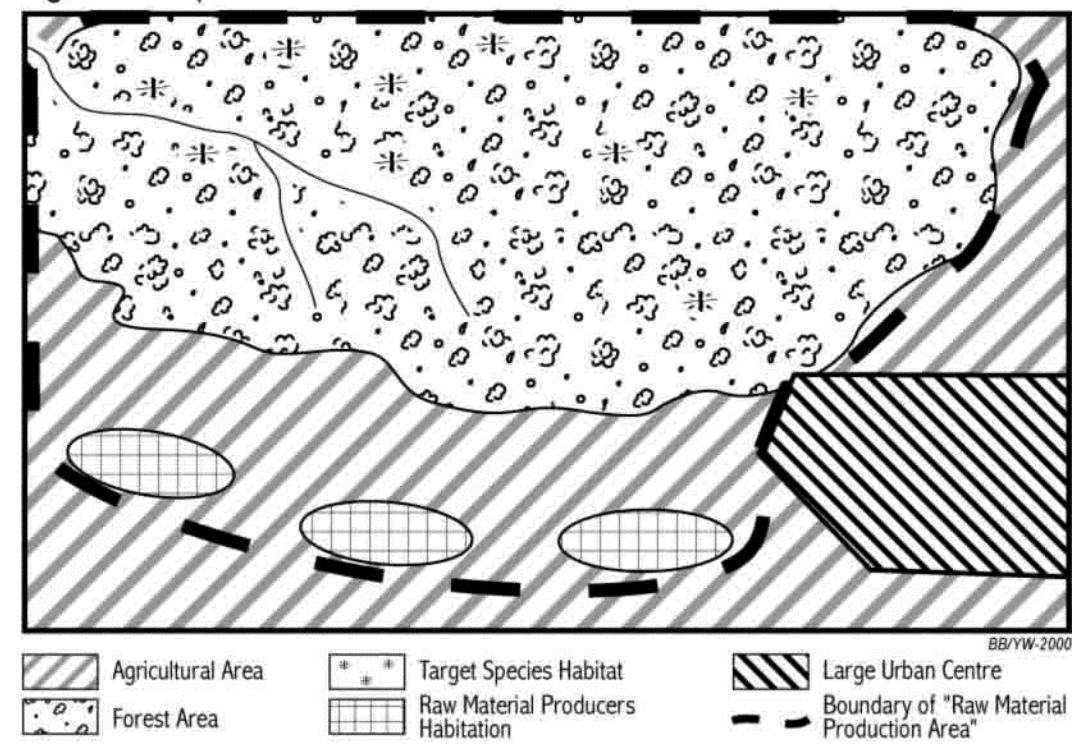

The trade/processing chain - the case also includes the downstream traders and product that originates in the selected raw material production area. The market/processing system may also be fed by raw material from other raw material production areas (i.e., other catchment areas). Some of the descriptors reflect a measurement of the proportion of the raw material that is obtained from the raw material production area selected for the case study. The market/processing chain may be quite short with sales by producers to final consumers (e.g., fruit), or it may be long with numerous intermediaries and processing steps (e.g., chemical inputs to pharmaceuticals produced in other countries). Information is required on processing that is done both within the country of origin and outside in foreign markets.

The final market - this includes all the buyers who ultimately consume the product in its final form. With some products there may be more than one or even several final markets with a proportion of the original raw material being used for different purposes and entering different markets. In these cases, the most important markets should be identified (collectively accounting for a minimum of $75 \%$ of the product consumption) and treated separately in the relevant sections of variables.
The narrative report should include a brief description of the case as it has been defined for that situation.

\section{DESCRIBING THE SYSTEM - CATEGORIES OF DATA}

The cases will be described according to a set of pre-defined variables or descriptors. In previous tests of the comparative method, we have used relative terms for many of the variables (Belcher et al. 2000). While this has been useful, strong limitations exist with such an approach due to its subjectivity and due to the need for a high level of knowledge of all cases by all participants to permit relative ranking. With a larger number of cases we need more objective measures. Wherever possible, we have suggested absolute variables of several kinds, including:

- Nominal variables (including dichotomous variables (yes or no) and categorical variables (e.g., classes such as leaf, seed, bark, stem, flower, or fruit)

- Ordinal variables (indicating the order in a sequence)

- Interval variables

- Ratio variables

We have also included trend variables to indicate the direction of change in a particular variable over a set period of time. 
The current set of descriptors was developed by the authors in conjunction with collaborators in the comparison of Indonesian forest products cases (Belcher et al. 2000), and in the current international comparison through various workshops and personal communication. The variables represent a compromise; they must be as precise and specific as possible, but the data requirements must not be too onerous. A variable is only useful in the comparative analysis if it is possible to get comparable data in each and every case.

The purpose of the descriptors has been a source of some confusion to collaborators. By nature, scientists strive for as much accuracy in their work as possible. So, there has been a tendency among collaborators to request more detail and more accuracy in the descriptors. It is important, therefore, to keep in mind that the main purpose of the descriptors is to provide a framework for comparing cases. We need robust accuracy more than spurious precision. The descriptors are not intended to be sufficient for a full analysis of an individual case by themselves. On the contrary, the premise for this work is that detailed analyses have been conducted by the researchers on the cases that they have studied. The descriptors will allow us to group cases with like cases and from there to seek patterns and theoretical understanding. In the course of the work we expect to be able to identify and select a sub-set of descriptors that are the most useful for this kind of classification. The overall comparative analysis will be facilitated by the classification of the cases, but will depend on the detailed analyses of the experts on the individual cases for the theoretical lessons.

The following discussion introduces the different categories of variables and provides the theoretical and practical rationale for the inclusion of the various descriptors.

\section{GEOGRAPHIC SETTING}

The context of an individual case is expected to have a strong influence on the kinds of products that are produced and on the opportunities and constraints for forest product development.

As discussed above, the definition of the case is extremely important. We have suggested an appropriate range for the spatial extent of the raw material production area ("catchment") to help guide case definition. For the analysis, an estimate of the actual spatial extent of the raw material production area is required to permit comparison.

Obviously human population size, density and dynamics (rate of growth) will have important influences on the development of the forest product system, as they influence competition for land, pressure on forest resources, market size and available infrastructure. Variables are included that account for the total population in the raw-material production area and population growth trends.

To characterize the raw material production area, variables are included to indicate predominant land uses (classified into eight major land-use categories), the forest type in the area (according to the Holdridge Classification system), the elevation, average precipitation, and the soil type (according to the FAO soils map of the world). The general level of development in the raw material production area will also influence forest product use and management decisions. One useful proxy for development is the level of communications/transportation infrastructure in the area. We have chosen to use a simple ratio of the total length of motorable roads and rail per square kilometre in the raw material production area. This is intended only as an indicator of development - descriptors in the section on trade and marketing deal with market access.

\section{CHARACTERISTICS OF THE PRODUCT}

This set of variables is intended to describe and categorize biological products according to their source, physical characteristics and uses. For classifying forest products, we use the basic divisions of plant, animal, fungus and forest service (including eco-tourism). These will be recorded as categorical variables. Many forest products have more than one use; the primary (most important by volume), secondary (second most important by volume) and tertiary (third most important by volume) uses should be recorded. For the purpose of classification, we subdivide the various forest products into use categories: food, animal feed, fibre (for weaving, paper, thatch, etc.), construction material (used for its structural properties), resins and dyes, medicinal/chemical, fuel or ornamental/aesthetic.

Understanding how the market works requires an assessment of whether the product is perishable or stable. An index is used here, defined as the 
number of days that a product (unprocessed, covered, at ambient temperature) can be kept before it loses $50 \%$ of its market value.

\section{CHARACTERISTICS OF THE PRODUCTION SYSTEM}

This category of descriptors focuses on the system by which the natural forest product is produced. Many forest products are extracted from the wild, but others are cultivated in some form or another. This is expected to be an important distinguishing factor.

The first variables included here measure the percentage of production that comes from three categories: wild ${ }^{2}$ (i.e., not cultivated); managed ${ }^{3}$ population in forest/natural environment; or domesticated $^{4}$ population. One variable deals with the relative importance of wild gathering in the case study area and a second deals with the relative importance of wild gathering in international production of the product. These variables are included to help determine whether the product has been domesticated locally or elsewhere (and therefore if it is technically possible to manage for increased quality or quantity of production) This is important to understand whether the case under study is more or less advanced in the production technology employed compared with production of the same or similar products in other places. A third variable is included to indicate whether or not there is a trend toward increasing intensity of management, something that is expected to have equity and sustainability implications.

There is, in effect, a continuum of production strategies from pure "extraction" through to intensive cultivation/husbandry (Belcher 1997). Economic theory predicts that people will

\footnotetext{
${ }^{2}$ Wild implies that the species is not managed there is no deliberate positive human intervention to improve productivity or quality (harvest limits may be applied).

${ }^{3}$ Management implies that labour and/or capital are invested to improve the productivity or the quality of product. The input may be as simple as weeding or protecting the target species, enrichment planting, fertilization, pruning, or other silvicultural or husbandry activities.

${ }^{4}$ Domesticated implies that the fungus, plant or animal species is cultivated and managed in a controlled environment, probably at higher than natural densities.
}

respond to increased commercial value of a product by intensifying production (Homma 1992; Godoy 1992). Some measure is needed of the degree of intensification. We have included variables measuring "labour intensity" and "technology intensity" as indicators of the level of management intervention in the production of the raw material. A "trend variable" is also included to capture information about whether the level of management is changing over time.

There is increasing evidence that people invest effort to encourage "wild production". Most forests are at least partially anthropogenic (Balee 1989; Posey 1984), and many valuable species have been established by, or with the help of, human effort. Large numbers of forest products are produced in secondary forest or fallow (Muniz-Miret et al. 1996; Fairhead and Leach 1996; Peluso and Padoch 1996; Peters 1996). A categorical variable is included to indicate the main source(s) of the product by land-use type ("habitat type").

The commercial potential of a product is at least partially determined by the seasonality of production. Variables are included that record both biological seasonality (owing to the phenology of the organism) and seasonality due to climatic, accessibility, technological, labour availability or other determinants.

Gender aspects of the work are important to consider as they are expected to influence/reflect the social organization of the production system. In some cases women are the primary harvesters, processors and marketers of forest products (Hecht et al. 1988; Falconer 1990; Terry and Cunningham 1993). In some cases, commercialization and new technology introductions may lead to displacement of women by men (Tewari and Campbell 1996). And there are distinct spatial differences between men's and women's activities (Ruiz-Pérez et al.1999; Schreckenberg 1996). A variable is included to indicate the percentages of time devoted by men and by women to the production of the raw material.

Many studies have shown that land and resource tenure is important in determining how land is used. People tend to be willing to invest more in land and resources over which they have secure control. Extractive-type activities are more likely under open access conditions. A variable is included to measure the percentage of production that is done under the four main 
categories of land tenure: private land, state land, communal land (common property) or open access.

Finally, to help indicate the minimum value of the system, we include a variable to measure the opportunity cost of the land. This is defined as the value of the land for its next best use. While this may be complicated in multiple use systems, it will still provide a potentially useful indicator.

\section{ECOLOGICAL IMPLICATIONS OF PRODUCTION}

A large proportion of the literature on forest product development and the projects and other interventions that have been implemented are concerned, at least in part, with "sustainable development". Sustainability implies that the target species is not over-exploited and that the ecosystem that provides the habitat for the target species is maintained in good condition (i.e., continues to function and provide ecosystem services). Several descriptors are included to characterize the species and its ecology and the vulnerability of the species and the system to damage from harvesting and management activities. These characteristics are expected to be useful in understanding sustainability and economic behaviour.

The vulnerability of the target species and its economic role will be determined, at least in part, by its distribution (geographic range and habitat specificity). Widely distributed species are less vulnerable to extinction. Species distribution may influence the range of markets. The biology and phenology of individual species are critical in determining levels of sustainable harvesting. Variables are included that characterize whether harvesting requires removal of the individual and that record regeneration period and reproductive period. We also want to know the degree to which harvesting activities affect the species growth or productivity and whether there is an impact of harvesting on the population of the resource being exploited.

We are also interested in the impact of harvesting and management on the ecosystem more broadly. It is recognized that accurate measures are difficult, will not be available in many cases and would be costly to obtain. Therefore, we have included several categorical (positive, neutral, negative) variables to provide general indicators. A variable is included to indicate the length of time the product has been commercially harvested. Actual impacts of harvesting activity on the population are indicated by measures of density and recruitment (defined as the proportion of mature individuals in the total population).

\section{SOCIO-ECONOMIC CHARACTERISTICS OF THE RAW MATERIAL PRODUCTION AREA}

One of the key issues that emerges from the literature is that many forest products are much more important to low income than to high income people (Pimental et al. 1997, Cavendish 1997; Falconer 1992; Hecht et al. 1988; Jodha 1986) There are many reasons for this pattern. Poor people have low opportunity costs of labour and higher level of need for some of these products. The products themselves are often available as open access resources, and there may be little competition from wealthier people as many are "inferior goods" that are displaced if people have physical access and can afford other products. Other studies note that at least some commercially valuable products are relatively more important for middle income households than for richer or poorer households in the same area (Ruiz-Pérez et al. 1999). One of the objectives of this study is to identify and better understand these patterns. Several variables are included to describe the socio-economic characteristics of the people involved in the raw material production. Some of these are absolute measures and others are relative to other groups. Variables are included for average household size and the number of people in a household that are involved in raw material production. A variable is included to indicate average household income (from all sources, including subsistence and barter as well as cash income). A variable is included for the national (or regional in large countries) average for household income for the year the case study was done to help understand how the raw material producers rank within the country, and for the year 1998 to facilitate the comparison across cases.

Theory predicts that as people become more integrated into the cash economy they will specialize more in the more valuable forest products and reduce their activities in less valuable subsistence activities (Godoy et al. 1995). A general indicator of "integration" of raw material producers into the cash economy is 
captured with a variable measuring the percentage of average incomes earned in cash.

As discussed above, people's use of forest products depends on the alternatives available. One measure of this is the "opportunity cost of labour". For the purpose of the comparison, this is defined as the average daily wage that people could get for alternate activities and it is captured as the variable "local labour rate".

It is valuable to know the relative importance of the production activity in the overall portfolio of economic activities in the area. This is captured with a variable measuring the proportion of households that are involved in raw material production. A trend variable is included to indicate whether this proportion is changing. Several variables are also included to capture relative contributions of the product to partial and total household income in the producer households and to measure the degree of specialization in forest product production. Another trend variable is included to capture information on whether the relative importance of the product in household income is changing.

Finally, it is important to know something about the status of the forest product producers. In many cases in the literature, forest work is seen as a low status occupation and people are quick to leave it for other opportunities to earn wages. This element alone may be important in determining the sustainability of a particular occupation. A variable named "social attitudes toward forest product production" is included to indicate the status of raw material producers both in the local context and in the national context.

\section{INSTITUTIONAL CHARACTERISTICS OF RAW MATERIAL PRODUCTION}

Many studies of extractive systems have shown that forest product producers, especially in extractive systems, tend to have weak bargaining positions relative to their buyers (Padoch 1992; Peluso 1992). This is due, at least in part, to characteristics typical of the products themselves - many forest products are produced in small batches in highly dispersed systems. Products are highly variable in quality and quantity with sharp seasonal fluctuations in supply due to the biology of the species (phenology; high interand intra-specific variability in production/yield) and competition for labour. Numerous market imperfections (especially poor information) characterize the markets. Also, many products are perishable, with low densities and scattered distribution, all factors that conspire to weaken the bargaining power of producers (Belcher 1997).

A frequent recommendation to overcome some of these inherent weaknesses is for producers to form associations (e.g., cooperatives) that would allow pooling of resources to facilitate investment in storage and post-harvest, collective bargaining, and generally improved bargaining positions (Neumann and Hirsch 2000). To characterize this aspect of the cases studied, variables are included that record the existence, effectiveness, age and level of participation in a producer organization.

It is also useful to understand whether or not anyone can become a producer of the product, or whether there are social, economic, technological or regulatory barriers that impede new households getting involved. This will have a strong bearing on the profitability of production, as some limitations on an increase in producers (and therefore increased supply) will help to maintain higher prices.

There may also be local ("traditional" or "customary") rules governing forest/product management (note - statutory regulations are covered in the next section). Variables are included to indicate whether these exist and to give a measure of their importance (i.e., whether they are respected by the people involved in producing the products and whether they have an impact on the management of the resource).

\section{POLICIES AFFECTING RAW MATERIAL PRODUCTION}

There is frequent mention of the importance of policy in forest product subsectors. The main policy instruments open to governments fall into three categories - regulation, incentives (positive and negative) and direct investment. It is a complex area and difficult to sort out the many issues. Variables used here focus on whether or not policy instruments falling into the three main categories are used with the intention of influencing the sector under study and whether and what kind of effect they have on production. A trend variable is included to indicate whether state intervention (policy) has generally increased, remained unchanged or decreased over the past ten years. 
Another major area of policy that influences forest product management is the ownership and legal recognition of that ownership. Variables are included to capture information on whether or not raw material producers have recognized legal right to harvest the product (through direct ownership, permit systems or other arrangements) and whether they have legal rights over the land itself. A trend variable is also included to record information about whether the legal recognition has changed, and in what direction, over the past ten years.

There is also a difference between de jure rights (those that exist in law) and de facto rights (those that exist in practice). If people believe that they own a resource, they will manage it accordingly. If they believe that their tenure is threatened, they are more likely to over-harvest (as witnessed in the China bamboo sector in the early days of the household responsibility (RuizPérez et al. 1999). A variable is included that addresses the issue of producer's awareness of their property rights.

The relationship between state and traditional laws may be complementary or in conflict. Past experience has shown this to be an important variable.

\section{CHARACTERISTICS OF THE PROCESSING INDUSTRY}

In the description of the characteristics of the product, we included physical and use properties. Likewise, we need to characterize the final product(s) that are produced from the natural product (raw material). If there is more than one important end product, the following descriptors should be completed for each. It is important to understand the processing of the product and the degree to which it is transformed from raw material to the final product. For example, raw fruit can be sold and consumed without any physical transformation. Other forest products, such as resins used as naval stores or plants used as chemical constituents, are completely transformed. It is difficult to devise an index of transformation, but a useful proxy is the proportion of value of the forest product in the finished product (e.g., the value of the rattan raw material in the consumer price of a rattan sofa set). The retail price of raw fruit will be the sum of the costs of storage, transportation and traders profits, with the cost of the fruit (the farm-gate price) making up a fairly large percentage. The farm-gate price of the damar resin used in paint formulation will be relatively much smaller. Another indicator of the degree of transformation of a product is the number of processing steps involved. A variable is included for the number of processing steps within the country and outside the country.

As in the production section, a variable is included to record the number of women involved in processing.

The processing technology used is important. Clay (1992), Arnold et al. (1994) and others have pointed out that low-cost, accessible processing technologies make it much easier for poor rural people to get involved. This relates to creation and capture of value at the community level; labour intensive technologies are more accessible than more capital intensive technologies. Although a number of attempts were made, we have not found a feasible, nonambiguous indicator of this measure. However, the scale of an operation is also important; this is captured with a variable that records the average size of processing units measured by the number of employees in an average processing unit (in the step with the largest numbers of employees per processing unit). For this variable, household members working in family enterprises are considered as employees. A descriptors is also included for the total number of processors.

As in the producer subsector, the level of organization among processors is important as are barriers to entry. Variables are included to indicate whether or not an organization exists, its age and the level of participation. Another variable records an assessment of whether or not the processor's organization is effective.

As in other subsectors, it is important to know whether and what kind of barriers exist to limit entry to the subsector.

Policy is also treated in a similar way as it was in the production subsector (above) with variables addressing regulations, incentives, direct investment, their respective effects and trends in state intervention. 


\section{CHARACTERISTICS OF TRADE AND MARKETING}

Many authors have emphasized the importance of understanding the market in any effort to develop a forest product (Warner 1995). Several variables are included to capture elements of the history, market trends, size and structure of the market.

It is interesting and useful to record the age of the market. Some markets are quite new (certain fruits, medicinal plants) while others have existed for hundreds of years (essences, spices). A trend variable is included to capture recent changes in the market. The size of the market is addressed through variables such as the total number of sellers (raw material producers), number of traders (at different levels) of raw material and of finished products, and the size of the trade of raw, semi-processed and final product (domestic and export) in US\$ terms. A variable is included to record the average price of the raw material at the farm gate. The importance of international markets in total trade is also measured in US\$ terms when appropriate and possible

Market structure and function is also affected by accessibility. Many forest products are produced in very remote areas. Two variables are included to indicate ease of access to the market by raw material producers: the walking distance to the nearest road, river or rail transport, and; the time required and mode of transportation to move the product to the main market. Market transparency is considered very important in the literature, but it is difficult to measure. It refers to the degree to which market participants know about prices, quality requirements, seasonality, and other issues relating to supply and demand in the market. Raw material producers are typically the least well informed and their lack of access to information often puts them in a position of "price-takers". We include three simple proportion variables to capture this information: the proportion of raw material sellers who know what their product is used for; the proportion that know the price of the raw material paid by second order traders, and; the proportion that know what grading standards are used by those traders.

As with the raw material, the perishability of the finished product has economic implications. At this stage the important question is how long it can be stored under typical storage conditions; refrigerated, frozen, canned or otherwise. A variable is included to indicate whether the finished product is subject to adulteration. Another variable captures information on the degree of variability in product quality by recording the price difference (in percentage terms) of high quality vs. low quality finished products.

Forest product markets are often characterized by a high level of "vertical integration" (defined as firms owning enterprises at different levels in the PCS - e.g., processing firms also owning raw material production or export and marketing firms). This is measured as a proportion of firms that have ownership in firms supplying their raw material and in firms involved in marketing and exporting. As with raw material production and processing, we include variables to capture the level of organization among traders, barriers to entry and kinds and effect and trend of state intervention in the sub-sector. Finally, in many forest product markets, corruption plays an important role. A variable is included to indicate whether the existing regulations encourage rent seeking behaviour (such as bribe-taking, illegal fees, etc.).

\section{OUTSIDE INTERVENTIONS}

With the recent interest in forest products, there has been increased attention to and investment in various aspects of forest product development. We try to capture and characterize this with a few variables that indicate whether there has been external support (donors, NGOs or private sector) to the system and then identify to which targets this support has been directed (i.e., raw material producers, traders, processing/manufacturing industry, retail/export industry). Variables are also included to identify the kind of intervention (financial support, technical support, organizational support, political support), the source of the external support, and whether or not there is a trend toward increasing or decreasing outside support.

\section{DEVELOPMENT AND CONSERVATION OUTCOMES}

Ultimately, we want to be able to identify different kinds of cases, characterized by certain variables or clusters of variables, and we want to relate these to outcomes in terms of conservation and development. 
Two approaches will be followed to characterize outcomes:

a) Some of the variables used for describing the various stages of the production-toconsumption system can also be used to characterize the development and conservation outcomes of the cases. Assessment of conservation outcomes will use variables such as the source of the product, information on trends toward intensification and all of the variables included in the section on Ecological Implications. Assessment of Development Outcomes will employ several socioeconomic variables, market trends and information about organization and rights.

b) We will also do an independent assessment of each case, using a qualitative assessment based on "expert judgement" by the case researchers and the CIFOR team. Key issues addressed will include:

- Welfare - has participation in the PCS contributed significantly to welfare, measured in terms of human, social, economic, man-made and environmental capital?

- Economic sustainability - will the PCS be economically viable in the medium to long term?

- Sustainable harvesting of the product is the product being managed on a sustainable basis?

- Ecological sustainability - is management leading to medium to long term conservation of the ecosystem?

- Conservation incentives- is the value of the forest product sufficient to encourage local conservation efforts?

Methods for this assessment are still being developed as part of the project.

The overall analysis will depend on the participation of experts from the individual cases. The process, underway at the time of printing, involves a series of regional workshops, with representatives from each case. Preliminary analysis will be done in advance of the workshop, but the final analysis will require the expert judgement of the collaborators.

The main outputs from this work will include:

1. Three edited books, one from each region. The books will include an introductory/overview chapter, chapters on each of the cases (authored by the collaborators), and chapters describing the results, discussing the outcomes, and drawing conclusions and recommendations.

2. Regional analyses

3. World-level analysis

4. A series of more detailed studies/assessments of key issues relevant to sub-sets of cases (classified on product, policy or other lines)

5. A decision support tool based on the analyses to help target support to forest products systems

6. A data-base of forest product case studies documented using a standardized approach as a basis for other research and synthesis work.

\section{ACKNOWLEDGEMENTS}

This paper, and the method it describes, has been through many iterations over a long period. The approach is constantly evolving, and we fully expect and intend that it will be further improved through implementation in the project that is now going on. The current version has benefited from the input of many colleagues. Neil Byron, a co-author of the concept paper, has been a willing and helpful sounding board at different stages. Our CIFOR colleagues working on the project with us - Ramadhani Achdiawan, Irdez Azhar, Bruce Campbell, Wil de Jong, Ousseynou Ndoye, Dede Rohadi, and Trish Shanley - have all contributed ideas, criticism and comments that have strengthened the approach. Tony Cunningham, Dale Dore and Pete Frost acted as external reviewers, and Miguel Alexiades has worked with us as a consultant - all four have provided invaluable feedback, notes of caution, and new ideas. Tony has subsequently participated in some related work and continued to help refine the approach. And, most importantly, this idea has gained from the inputs of more than 70 collaborators all over the world who have worked to apply the method and have helped to improve it where they found it wanting. We thank them for this and for their patience with a sometimes tedious process. All the problems and errors that remain are our responsibility, and we look forward to sorting them out as we progress. Finally, we gratefully acknowledge the support of DFID and of CIFOR's core donors that have made it possible to implement this collaborative research project. 


\section{REFERENCES}

Arnold, J.E.M., Liedholm, C., Mead, D. and Townson, I.M. 1994 Structure and growth of small enterprises in the forest sector in Southern and Eastern Africa. O.F.I. Occasional Papers: 34

Balee, W. 1989 The culture of Amazon forests. Adv. in Econ. Bot. 7:1-21.

Belcher, B.M. 1997 Commercialization of forest products as a tool for sustainable development: lessons from the Asian rattan sector. Ph.D. Thesis, University of Minnesota, U.S.A.

Belcher, B.M. 1998 A production-toconsumption systems approach: lessons from the bamboo and rattan sectors in Asia. In: Wollenberg, E. and Ingles, A. (eds.). Incomes from the forest: methods for the development and conservation of forest products for local communities, 5784. Center for International Forestry Research, Bogor, Indonesia.

Cavendish, M.W.P. 1997 The economics of natural resource utilization by communal area farmers of Zimbabwe. Ph.D. Thesis, University of Oxford, UK.

Clay, J. 1992 Buidling and supplying markets for non-wood tropical forest products. In: Cousell, S. and Rice, T. (eds.). The rainforest harvest: sustainable strategies for saving the tropical forests? 250-255. Friends of the Earth, London.

Fairhead, J. and Leach, M. 1996 Misreading the African landscape: society and ecology in a forest-savanna mosaic. University of Cambridge Press, Cambridge.

Falconer, J. 1990 The major significance of minor forest products - examples from West Africa. Appropriate Technology 17(3):13-16.

Falconer, J. 1992 A study of the non-timber forest products of Ghana's forest zone. In: Cousell, S. and Rice, T. (eds.) The rainforest harvest: sustainable strategies for saving the tropical forests? 135-141. Friends of the Earth, London.

Hecht, S.B., Anderson A.B. and May, P. 1988 The subsidy from nature: shifting cultivation, successional palm forests, and rural development. Human Organization 47(1):25-35.

Homma, A.K.O. 1992 The dynamics of extraction in Amazonia: a historical perpective. In: Nepstad, D.C. and
Schwartzman, S. (eds.) Non-timber products from tropical forest: evaluation of a conservation and development strategy. Advances in Economic Botany 9, 23-31. The New York Botanical Garden, Bronx, New York.

Jodha, N.S. 1986 Common property resources and rural poor in dry regions of India. Economic and Political Weekly 21(27):1169-1181.

Maogong, Z., Maoyi, F., Belcher, B. and Ruiz Pérez, M. 1997 Analysis of social economy and policies on production management systems. A case study on China's bamboo industry. Forestry Economics 5: 50-58 (in Chinese).

Muniz-Miret, N., Vamos, R., Hiraoka, M., Montagnini, F. and Mendelsohn, R.O. 1996 The economic value of managing the acai palm (Euterpe oleracea Mart.) in the floodplains of the Amazon estuary, Para, Brazil. Forest Ecology and Management, 87:163-173.

Neumann, R.P. and Hirsch, E. 2000. Commercialization of non-timber forest products: review and analysis of research. Center for International Forestry Research, Bogor, Indonesia.

Padoch, C. 1992 Marketing of non-timber forest products in Western Amazonia: general observations and research priorities. In: Nepstad, D.C. and Schwartzman, S. (eds.) Non-timber products from tropical forest: evaluation of a conservation and development strategy. Advances in Economic Botany 9, 43-50. The New York Botanical Garden. Bronx, New York.

Peluso, N.L. and Padoch, C. 1996 Changing resource rights in managed forests in West Kalimantan. In: Padoch, C. and Peluso, N.L. (eds.). Borneo in transition: people, conservation, and development, 121-136. Oxford University Press, Oxford.

Peluso, N.L. 1992 The rattan trade in East Kalimantan, Indonesia. In: Nepstad, D.C. and Schwarzman, S. (eds.) Non-timber products from tropical forest: evaluation of a conservation and development strategy. Advances in Economic Botany 9, 115-127. The New York Botanical Garden, Bronx, New York.

Peters, C. M. 1996 Illipe nuts (Shorea spp) in West Kalimantan: use, ecology, and 
management potential of an important forest resource. In: Padoch, C. and Peluso, N.L. (eds.). Borneo in transition: people, conservation, and development, 230-244. Oxford University Press, Oxford.

Pimentel, D., McNair, M., Buck, L., Pimental, M. and Kamil, J. 1997 The value of forests to world food security. Human Ecology 25(1):91-120.

Posey, D.A., 1984. A preliminary report on diversified management of tropical forest by the Kayapo Indians of the Brazilian Amazon. Adv. in Econ. Bot. 1:112-126

Rohadi, D., Maryani, R., Belcher, B., Ruiz Pérez, M. and Widyana, M. 2000 Can sandalwood in East Nusa Tenggara survive? Lessons from the policy impact on resource sustainability. Sandalwood Research Newsletter, 10:3-6.

Ruiz Pérez, M., Maoyi, F., Belcher, B. and Xiaosheng, Y. 2000 The potential of bamboo resources in mountainous China. In: Price, M.F. and Butt, N. (eds.) Forests in sustainable mountain development: a state of knowledge report for 2000, 318326. IUFRO Research Series No 5 CABI Publishing, Oxon (UK) and New York (USA).

Ruiz-Pérez, M., Zhong M., Belcher, B., Xie, C., $\mathrm{Fu}, \mathrm{M}$. , and Xie, J., 1999. The role of bamboo in rural development: the case of Anji County, Zhejiang, China. World Development. Vol 27 No 1:101-114.

Ruiz-Pérez, M. and N. Byron, 1999. A methodology to analyze divergent case studies of non-timber forest products and their development potential. Forest Science 45(1) pp. 1-14.

Ruiz-Pérez, M. and Arnold, M. (eds.). 1997 Current issues in non-timber forest products. Center for International Forestry Research, Bogor, Indonesia.

Schreckenberg, K. 1996 Forests, fields and markets: a study of indigenous tree products in the woody savannas of the Bassila region, Benin. Ph. D. Thesis, London University, U.K.

Shanley, P., Pierce, A.R., Laird, S.A. and Guillen, A. forthcoming. Tapping the green market. Earthscan Press.

Terry, M.E. and Cunningham, A.B. 1993 Impact of commercial marketing on the basketry of Southern Africa. Journal of Museum Ethnography 4:25-48.

Tewari, D.D. and Campbell, J.Y. 1996 Increased development of non-timber forest products in India: some issues and concerns. Unasylva 47(187): 26-31.

Townson, I.M., 1994. Forest products and household incomes: a review and annotated bibliography. Oxford Forestry Institute.

Warner, M.W. and Balcombe, K. 1996 How useful is gender in explaining the economic roles of Africa's rural peoples? an application in logistic regression analysis. Series in Empirical Agricultural Economics and Econometrics No 5:20. 


\section{ANNEX I. DESCRIPTORS}

\section{Background to case study}

1. Year of data. Give the year that your yearspecific data refers to. While we will attempt to standardize by using 1998, enter a different date here if the bulk of the data does not come from 1998. Individual variables may come from different years. If that is the case, specify the year next to those variables.

2. Background to study. In a few sentences indicate the purpose of the original study (or studies) - whether academic research, rural development, conservation project, consulting report, or other - and a note on the scope and duration of the research.

3. Species name. Give the scientific name, trade name and common name of the species for the case. In some case, more than one species will be mentioned - try to give an assessment of the relative importance (in volume terms) of the different species.

4. Locality of raw material production area Province, district, township, etc.

5. Country.

6. Latitude and longitude.

7. Names of collaborators. Where different collaborators are contributing different sets of data for the same case, indicate this on the spreadsheet.

\section{A. Geographic Setting}

1. Spatial extent of the raw material production area - Size of the raw material production area in the case study in square kilometers. In cases where the forest/collection area and the village area are adjacent to each other, the spatial extent is the sum of these two areas. Where the village area is embedded in the collection area, then it is the area that people in those villages use to collect the forest product.

2. Human population size - Number of people in the raw material production area of the case study (including adjacent settlement areas). This number includes all people living in the area, not just those engaged in the forest product production to consumption system (PCS). Large urban centres should be excluded from the raw material production area.
3. Human population growth trend - Has the human population in the area increased, remained stable or decreased over the past 10 years (including changes due to migration $)^{5}$ ?

4. Predominant land-use - Major land uses in the raw material production area, recorded in terms of absolute area (in square kilometers) by the following categories: rainfed crop production; irrigated crop production; permanent crops; pasture (includes savannahs/woodlands which are used for grazing); swidden fallow; forest; settled area; marshy/swamped.

5. Level of available transportation infrastructure - Total length of motorable roads and rail per square kilometer in the 100,000 ha area centered on the raw material production area.

6. Forest Type - Forest type according to Holdridge classification system.

7. Elevation of raw material production area Mean elevation ( $m$ a.s.l.) of raw material production area

8. Soil Type - Predominant soil type, as derived from the FAO Soils Map of the World.

9. Precipitation - Average annual precipitation of raw material production area in $\mathrm{mm}$.

\section{B. Characteristics of the Product}

1. Source of Product

(i) Animal

a . Whole or part of carcass, hides (harvesting kills animal)

b. Products made by animal, such as honey, silk, or bird nest (harvesting does not kill animal)

(ii) Plant

c. Vegetative structure (leaves, branches, stem, bark, root)

d. Reproductive propagules (flowers, fruits, seeds, other)

e. Plant product (exudate: latex, resin, gum)

f. Product of parasitic infection of plant (e.g., stick lac; gaharu)

(iii) Fungus

g. mushroom

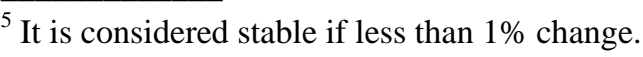


(iv) Forest

h. Tourism

i. Ecological Services

2. Use of product

Using the list below, indicate the first, second and third most important use of the product (on a volume basis). In this question, use includes subsistence or commercial use. Select only one product per column. forest; Secondary forest ( $>10$ years old; part of a forest system); Savanna/woodland; Fallow (part of an agricultural system); Agricultural fields (e.g. with very few scattered trees); Plantation; Agroforest; Coastal/wetland). (If this classification does not work for your particular study site, then please add the appropriate categories, and explain the categories)

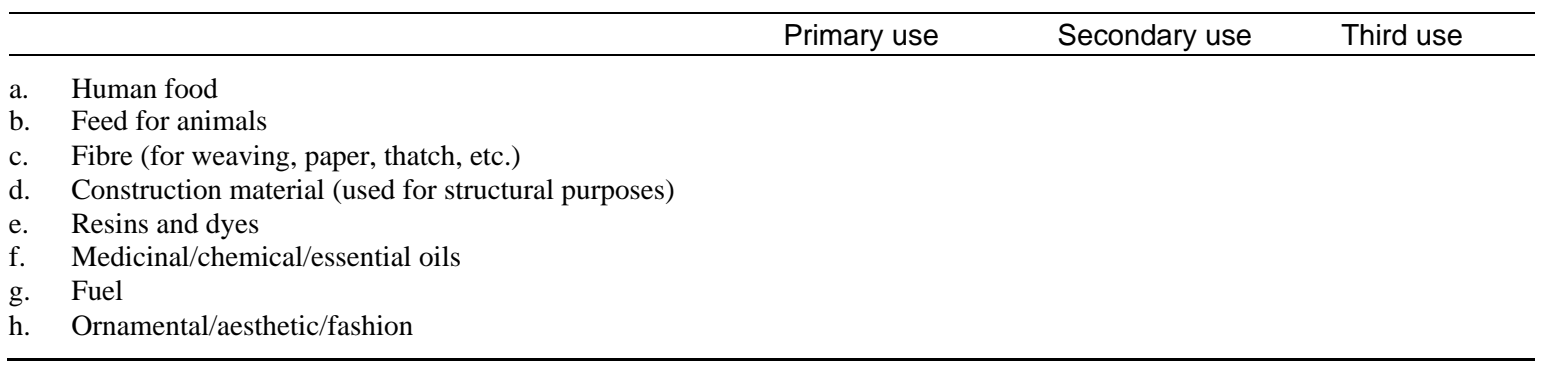

3. Perishability of the product - Number of days at ambient temperature but under cover for the harvested forest product (air-dried if applicable) to lose $50 \%$ of its farm-gate value.

\section{Characteristics of the Production System}

1. Importance of wild gathering (vs. managed and cultivated) in raw material production area - \% of annual production in the raw material production area that is collected from (i) wild (natural reproducing) population, (ii) managed population in a forest/natural environment and (iii) cultivated population.

2. Importance of wild gathering (vs. managed and cultivated) in international production of product -Is there significant national or international commercial production of this product that is harvested from:

a. wild (naturally reproducing) population? (yes or no)

b. managed population in a forest/natural environment? (yes or no)

c. cultivated population? (yes or no).

3. Trend towards increasing intensification in raw material production area - Percentage increase in annual production from a managed/cultivated/ domesticated resource in past 10 years

4. Habitat type - Percentage of annual production of product in the raw material production area from the following habitat types: Primary forest; Disturbed primary
5. Length of biological harvesting season (months of harvest/year) - Number of months per year that harvesting can be done according to biological limits of organism

6. Length of effective harvesting season (months of harvest/year)- Number of months per year that harvesting is actually done according to climatic limitations (e.g., rainy season prevents access; high humidity limits processing), cultural norms, market demands (e.g., sales only in particular festive seasons), or government regulations (e.g., hunting seasons)

7. Production Technology: labour intensity Average person-days/ha/year for growing and harvesting product (not including transport to/from the harvesting area).

8. Production Technology: technology intensity - Average cost (US\$) of inputs (other than labour) per ha per year for growing and harvesting the product (this covers tools, bullets, fertilizers, pesticides, etc.). The cost of large capital items lasting more than a year should be averaged over the typical life of the item

9. Gender representation in production Percentage of production and harvesting labour done by women

10. Land Tenure - Percentage of production that is done on different land tenure categories (note that resource rights are covered in a later section)
a. Private land
b. State land
c. Communal land (common property)
d. Open access 
11. Value of the land - (a) US\$/ha/year if rented; (b) US\$/ha if sold; (c) US\$/ha/year if concession fee.

\section{Ecological Implications of Production}

1. Geographic range - total area (global) over which the target species lives: large $(>1,000,000 \quad \mathrm{~km} 2) ; \quad$ medium $(<1,000,000>75,000 \mathrm{~km} 2)$; small $(<75,000$ $\mathrm{km} 2)$.

2 Habitat specificity - range of habitats ${ }^{6}$ where target species can live: wide (many habitats); moderate (2-3 habitats); narrow (1 habitat).

3 Regeneration period - Time (in years) from germination (birth) to harvesting maturity

4 Reproductive period - Time (in years) from germination (birth) to reproductive maturity

5 Life span - Average life span of individual (in years)

6 Impact of harvest on individual - Effect of harvesting on the individual (kills, damages or neutral)

7 Impact of harvest on target species - Effect of harvesting on local population of target species (population is declining, stable or increasing)

8 Impact of harvest on the ecosystem: (negative, neutral or positive)

9 Impact of harvest on dependent organisms: (negative, neutral or positive)

10 Exploitation history - length of time resource has been exploited commercially from the raw material production area (in years).

11 Density - number of economically harvestable individuals per ha.

12 Recruitment - percentage of mature individuals ((mature individuals/total individuals) $X$ 100) in raw material harvesting area $^{7}$

\section{E. Socio-economic Characteristics of the Raw Material Production Area}

1. Average household ${ }^{8}$ size - Average number of people per household in raw material production area

\footnotetext{
${ }^{6}$ Habitats defined above in $\mathrm{C} 4$

7 "Harvesting area" may be a smaller area or areas within the raw material production area, where the product is actually harvested

8 "Household" designates a unit of production not a unit of social organization, though in practice these will often overlap.
}

2. Numbers of producers ${ }^{9}$ per household Average number of people involved in production per producer-household

3. Average annual household income Average total annual (subsistence+barter+cash) household income in raw material production area in US\$ equivalent. Clarify the extent to which the data really represents subsistence use (e.g., many income statistics may incorporate agricultural subsistence, but not that due to forest products - please clarify the nature of all the income data)

4. National ${ }^{10}$ annual household income for data year - National average household income (US\$) for the year of data collection

5. National annual household income for 1998 - National average household income (US\$) for the year 1998 (to explore crosscase comparability we will attempt to get data for a common year - the previous question reflects the reality that the bulk of data from the studies may not come from 1998)

6. Integration into cash economy - Percent of average total income (subsistence+ barter+cash) of households in raw material production area that is earned in cash

7. Local labour rate - Average daily wage for labour in raw material production area in US\$ equivalent

8. Proportion of households involved in PCS Percentage of households in the raw material production area that are involved in: (a) production, (b) processing, (c) marketing and (d) production and/or processing and/or marketing. Generally (a), (b) and (c) do not sum up to give (d) as many households may be doing more than one function.

9. Trend of household involvement in PCS Has the percentage of households involved in production, processing and marketing the product increased, remained stable or decreased?

10. Average household income of producer households - Average annual household income (cash+subsistence+barter) of producer households in US\$ equivalent.

11. Degree to which product contributes to household income of producers - Percentage

\footnotetext{
9 'Producer' covers collectors and harvesters

${ }^{10}$ For large countries (e.g. Brazil, India), with large differences between states, please give national and state figures for E4 and E5.
} 
of average producer-household total income (subsistence+barter+cash) derived from the product

12. Numbers of products in the NTFP portfolio - How many other NTFPs are produced per producer household for trade (inclusive of barter)? O-2, 3-5, 6 or more (averages per household)

13. Trend of income from forest product production - Has relative household income from production of the forest product increased, remained stable or declined over the past ten years?

14. Social attitudes toward forest product production:

a . Within the local community, do producers of the product have high, medium or low status, or no particular status?

b. At the national level, do producers of the product have high, medium or low status, or no particular status?

\section{F. Institutional Characteristics of Producers}

1. Level of organization among raw material producers- Is there a raw material producers' organization that deals with the product in question (no; informal; formal)?

2. Effectiveness of organization - If yes, is its effect on the producers generally positive, neutral or negative?

3. Age of organization - If there is a producers' organization, what is its age in years?

4. Degree of participation in organization - $\%$ forest product producers who participate in a producers' organization

5. Barriers that impede new households getting involved in production of the product - Are there barriers that make it difficult for new producers to enter? (yes or no)

a. Social barriers (local rules, restrictions of caste, family or ethnic ties)

b. Economic barriers (the costs of entry are too high for some)

c Technical barriers (production/processing requires special skills or knowledge)

d. Regulatory barriers (laws preventing entry)

6. Customary rules governing forest/product use - Are there local (traditional or customary; non-statutory) rules governing access to and management of the product (yes or no)?
7. Respect by community of their customary laws - (a) do raw material producers generally respect the traditional rules governing access to and management of the product?(yes or no) (b) are the rules effectively enforced? (yes or no)

8. Effectiveness of customary rules - Is the effect of traditional rules governing access and management of the forest product generally positive, neutral or negative in: (a) influencing exploitation of the resource for the product in question (positive would mean resource exploitation is tending towards being sustainable); (b) promoting equitable access to the resource (positive means equitability is promoted); (c) influencing total production (positive means production is increased). If "Negative" for (b), what groups are dominating resource access?

\section{G. Policies Affecting Raw Material Production}

1. Government regulations

a. Are there current regulations/rules that are intended to influence the production of the product (raw material) (yes or no)?

b. If yes, is their effect generally positive, neutral or negative in: (a) influencing exploitation of the resource (positive would mean resource exploitation is tending towards being sustainable); (b) promoting equitable access to the resource (positive means equitability is promoted); (c) influencing total production (positive means production is increased). If "Negative" for (b), what groups are dominating resource access?

2. Incentives (tax, subsidies, etc.)

a. Are there taxes, fees or subsidies that are intended to influence the raw material production of the product (yes or no)?

b. If yes, is their effect generally positive, neutral or negative in: (a) influencing exploitation of the resource (positive would mean resource exploitation is tending towards being sustainable); (b) promoting equitable access to the resource (positive means equitability is promoted); (c) influencing total production (positive means production is increased). If "Negative" for (b), 
what groups are dominating resource access?

3. Government direct investment (research, extension, direct ownership)

a. Is there government investment to support, encourage or develop raw material production of the product (yes or no)?

b. If yes, is their effect generally positive, neutral or negative in: (a) influencing exploitation of the resource (positive would mean resource exploitation is tending towards being sustainable); (b) promoting equitable access to the resource (positive means equitability is promoted); (c) influencing total production (positive means production is increased). If "Negative" for (b), what groups are dominating resource access?

4. Trend of state intervention - Has state intervention in the raw material production of the product generally increased, remained unchanged or decreased in the past ten years?

5. Legal Recognition/Resource Tenure

a. Do raw material producers have recognized legal right to harvest the product for trade? (yes or no)

b. Do raw material producers have recognized legal right to change the land use to another production system? (yes or no)

6. Trend in legal recognition - Have the legal rights of raw material producers to harvest the product for commercial purposes improved, remained unchanged or worsened in the past ten years?

7. Knowledge by community of their legal rights - Are the raw material producers in the community generally aware of the nature of their legal rights to harvest the product for commercial purposes (yes or no)?

8. Legal action to claim land-Have there been any official claims by producers to increase land/resource rights over the last 10 years (yes or no)?

9. Relationship between state and traditional (local) laws - Are state laws and traditional (local) rules conflicting, complementary or neutral to each other with regard to the product in question?

\section{H. Characteristics of the Processing Industry}

If there is more than one important end product, this section would be repeated, once for most important (by volume) commercialized end product, and once for the second most important end product. The questions in this section refer to the entire $P C S$, not just in the raw material production area.

State the most important product and second most important product (e.g., for a case of the baobab tree, one could have bark as the most important product and fruit as the second most important product).

1. Product (Use categories in section B, question 2)

2. Degree of transformation from raw material to finished product - Rank the degree of processing that is required as low (e.g., fruit, bush meat or other products that can be used directly by the consumer), medium (e.g., fibre from grass used for weaving or handicrafts; wood for carvings) or high (e.g., essential oil extracted from plant and used in incense or as a chemical component in medicine).

3. Proportion of value of forest product in finished product - Value of the raw material (farmgate price) as a percentage of the value of the final product in the main market.

4. Processing steps - What is the number of major processing steps (e.g. drying; powdering; distilling; packaging) done (a) in country, and (b) out of country ${ }^{11}$ ? Please list the steps in comments.

5. Size of processing unit-Average number of employees (including household members) per processing unit in the step with the largest numbers per processing unit ( 1-5, 610, 11-50>50). . In some cases a processing unit will be a household-run operation, in others a factory which hires employees.

a) in country

b) out of country

6. Gender representation in processing Percentage of processing labour done by women

\footnotetext{
${ }^{11}$ Information on out-of-country processing (H4, H5) may be omitted if it is too difficult to obtain.
} 
7. Total number of processors - What is the number of processing units using raw material originating in the raw material production area

8. Level of organization among processors - Is there a formal organization concerned with the processing of the product in question among the processors at the lowest level (primary processors)? (yes or no)

9. Age of organization - If yes, what is the age of the processors organization in years

10. Degree of participation in organization - $\%$ processing units that participate in the processors' organization

11. Effectiveness of processors' organization Does the processing organization have a positive, neutral or negative effect on the bargaining power of processors?

12. Barriers to entry - Are there barriers that make it difficult for new processing units to enter the industry? (yes or no)

a. Social barriers (local rules, restrictions of caste, family or ethnic ties)

b. Economic barriers (the costs of entry are too high for some)

c. Technical barriers (processing requires special skills or knowledge)

d. Regulatory barriers (laws preventing entry)

12. Regulation -

a. Are there current regulations/rules that are intended to influence the processing subsector? (yes or no)

b. If yes, is their effect on total production generally positive, neutral or negative?

13. Incentives (tax, subsidies, etc.)

a. Are there taxes, fees or subsidies that are intended to influence the processing sector? (yes or no)

b. If yes, is their effect on total production generally positive, neutral or negative?

14. Direct Investment (research, extension, direct ownership)

a. Is there government investment to support, encourage or develop the processing of the product? (yes or no)

b. If yes, is the effect on total output of processed product generally positive, neutral or negative?

15. Trend of state intervention - Has state intervention in the processing of the product increased, remained unchanged or decreased in the past ten years?

\section{Characteristics of Trade and Marketing}

If there is more than one important final product, this section would be repeated, once for most important (by volume) end product, and once for the second most important end product

1. Product (Use categories in section $B$, question 2)

2. Age of market - How long has the product been traded from the raw material production area? (in years)

3. Market trend - Has the market for this product expanded, remained stable, contracted or shown boom/bust characteristics in the past 10 years (refers to the PCS)?

4. Total number of raw material traders in the PCS - What is the absolute number of:

a. first order traders (traders who buy from raw material producers) involved in trading products that originate in the raw material production area?

b. $\quad$ second order traders (traders who buy from first order traders) involved in trading products that originate in the raw material production area?

c. $\quad$ third order traders in the PCS (traders who buy from second order traders) involved in trading products that originate in the raw material production area?

5. Trade opportunities for raw material producers - To what extent do raw material producers have a choice of who they sell their product to? (they can sell to 1 buyer, 24 buyers, $>4$ buyers)

6. Price of raw material - what is the average US\$price/kg. of the raw material at the farm-gate (forest-gate)?

7. Distance to transportation network Walking distance in $\mathrm{km}$ from raw material production area to nearest road, river or rail transport.

8. Distance to markets - (a) time required to travel from raw material production area to market? (b) what is the mode of travel?

9. Size of the trade in raw material production area - What is the total annual farmgate value (in US\$ terms) for the trade of the raw material originating from the raw material production area (farmgate prices)? 
10. Size of national trade - What is the total annual farmgate value (in US\$ terms) for the national trade of the raw material in the country (farmgate prices), including all production areas?

11. Size of raw and semi-processed products export trade - What is the value (in US\$ terms) of the total national export of raw and semi-processed product (Free on Board (FOB) prices))

12. Total number of finished products traders in the $\mathrm{PCS}^{12}$ - What is the absolute number of:

a. first order traders (traders who buy from manufacturers) involved in trading products that originate in the raw material production area?

b. second order traders (traders who buy from first order traders) involved in trading products that originate in the raw material production area?

c. third order traders in the PCS (traders who buy from second order traders) involved in trading products that originate in the raw material production area?

13. Size of finished products export trade What is the value (in US\$ terms) of the total national export of finished products using the raw material (from all production areas, not only the raw material production area of the case)

14. Market transparency -

a. percentage of raw material producers that know accurately what the product is used for

b. Percentage of raw material producers that know accurately the price paid for raw material by second order traders

c. Percentage of raw material producers that know accurately the grading standards used by second order traders

15. Perishability of finished product - Number of days under typical storage conditions for the finished product to lose $50 \%$ of its value.

16. Product adulteration - Is the finished product subject to adulteration (e.g,. being watered down, other substitutes added)? (always, occasionally, never).

17. Price variation - How much higher is the price (in percentage terms) of high priced finished products compared to low priced

\footnotetext{
12 This question is especially relevant for handicrafts (e.g. wood carving, basket making)
}

finished products of the same kind (function)?

18. Importance of "vertical integration" Percentage of processing firms that have ownership in:

a. firms supplying their raw-material

b. export and marketing firms (in this question we are considering processing firms that are using raw materials from the raw material production area)

19. Level of organization among traders - Is there a formal trade organization? (yes or no)

20. Age of organization - If yes, what is the age of the trade organization in years?

21. Degree of participation in organization - $\%$ of traders that participate in the trade organization

22. Barriers to entry - Are there barriers that make it difficult for new traders to enter the business? (yes or no)

a. Social barriers (local rules, restrictions of caste, family or ethnic ties)

b. Economic barriers (the costs of entry are too high for some)

c. Technical barriers (marketing requires special skills or knowledge)

d. Regulatory barriers (laws preventing entry)

23. Intensity of state involvement affecting forest product trade - A measure of the degree to which state tries to influence the sector through the main policy instruments of:

- (i) Regulation

a. Are there current regulations/ rules that are intended to influence the trade of the product? (yes or no)

b. If yes, is their effect on total trade generally positive, neutral or negative?

- (ii) Incentives (tax, subsidies, etc.)

a. Are there taxes, fees or subsidies that are intended to influence the trade of the product? (yes or no)

b. If yes, is their effect on total trade generally positive, neutral or negative?

- (iii) Direct Investment (research, extension, direct ownership)

a. Is there government investment to support, encourage or 
develop the trade of the product? (yes or no)

b. If yes, is the effect on total trade generally positive, neutral or negative?

24. Trend of state intervention - Has state intervention in the trade of the product increased, remained unchanged or decreased in the past ten years?

25. Corrupt practices - Do the regulations create conditions that encourage illegal costs for the trade?(Yes or no)

\section{J. Outside Interventions}

1. External support for forest product production/producers/processing/trading Have there been outside interventions from donors or NGOs (yes or no) to support the PCS in terms of:
a. financial support
b. technical support (training, technical backstopping, etc.)
c . organizational support (capacity building)
d. political support and advocacy

2. Target of external support - Has external support from donors or NGOs been targeted to

a. Raw material producers (yes or no)

b. Traders (yes or no) c Processing/manufacturing industry
(yes or no)

d. Retail/export industry (yes or no)

3. Trend toward increasing or decreasing outside support - Has outside support from the donors or NGOs increased, remained stable or decreased to the following:
a. Raw material producers
b. Traders
c. Processing/manufacturing industry
d. Retail/export industry

4. External support for forest product production/producers/processing/trading Have there been outside interventions from the private sector (yes or no) to support the PCS in terms of:
a. financial support
b. technical support (training, technical backstopping, etc.)
c. organizational support (e.g. capacity building)
d. political support and advocacy

5. Target of external support - Has external support from the private sector been targeted to:
a. Raw material producers (yes or no)
b. Traders (yes or no)
c. Processing/manufacturing industry (yes or no)
d. Retail/export industry (yes or no)

6. Trend toward increasing or decreasing outside support - Has outside support from the private sector increased, remained stable or decreased to the following:
a. Raw material producers
b. Traders
c. Processing/manufacturing industry
d. Retail/export industry

7. Source of external support - What is the main source of external support:
a. Local/national NGO
b. International $N G O$
c. Foreign government
d. National private sector
e. International private sector 
